\title{
Characterization of the first two toxins isolated from the venom of the ancient scorpion Tityus (Archaeotityus) mattogrossensis (Borelli, 1901)
}

\author{
Natiela Beatriz de Oliveira ${ }^{1}$, Ana Carolina Martins Magalhães ${ }^{1}$, Carlos Bloch Jr. ${ }^{2}$, Paulo Sérgio Lacerda Beirão ${ }^{3}$, \\ Anita de Oliveira Silva ${ }^{3}$, Rafael D. Melani ${ }^{1}$ (D), Eder Alves Barbosa ${ }^{2,4}$, Osmindo Rodrigues Pires Júnior ${ }^{1 *}$ (D), \\ Carlos Alberto Schwartz ${ }^{1 \dagger}$ \\ 'Laboratory of Toxinology, Department of Physiological Sciences, Institute of Biology, University of Brasilia (UnB), Brasília, DF, Brazil. \\ ${ }^{2}$ EMPRABA Center of Genetic Resources and Biotechnology, Brazilian Agricultural Research Corporation, Brasília, DF, Brazil. \\ ${ }^{3}$ Department of Biochemistry and Immunology, Institute of Exact Sciences, Federal University of Minas Gerais (UFMG), Belo Horizonte, MG, Brazil. \\ ${ }^{4}$ Laboratory of Biomolecule Synthesis and Analysis, Institute of Chemistry, University of Brasilia (UnB), Brasília, DF, Brazil.
}

\section{Keywords:}

Archaeotityus

Scorpion

Tityus (Archaeotityus) mattogrossensis Toxins

\begin{abstract}
Background: Almost all Tityus characterized toxins are from subgenera Atreus and Tityus, there are only a few data about toxins produced by Archaeotityus, an ancient group in Tityus genus.

Methods: Tityus (Archaeotityus) mattogrossensis crude venom was fractionated by high performance liquid chromatography, the major fractions were tested in a frog sciatic nerve single sucrose-gap technique. Two fractions ( $\mathrm{Tm} 1$ and $\mathrm{Tm} 2)$ were isolated, partially sequenced by MALDI-TOF/MS and electrophysiological assayed on HEK293 Nav 1.3, HEK293 Nav 1.6, DUM and DRG cells.

Results: The sucrose-gap technique showed neurotoxicity in four fractions. One fraction caused a delay of action potential repolarization and other three caused a reduction in amplitude. An electrophysiological assay showed that Tm1 is active on HEK293 Nav 1.3, HEK293 Nav 1.6, DUM and DRG cells, and Tm2 on HEK293 Nav 1.3 and DRG cells, but not in HEK293 Nav 1.6. In addition, $\mathrm{Tm} 1$ and $\mathrm{Tm} 2$ did promote a shift to more negative potentials strongly suggesting that both are $\alpha$-NaScTx.

Conclusion: Although Tityus (Archaeotityus) mattogrossensis is considered an ancient group in Tityus genus, the primary structure of $\mathrm{Tm} 1$ and $\mathrm{Tm} 2$ is more related to Tityus subgenus. The patch clamp electrophysiological tests suggest that $\operatorname{Tm} 1$ and $\operatorname{Tm} 2$ are $\mathrm{NaScTx}$, and also promoted no shift to more negative potentials, strongly suggesting that both are $\alpha-\mathrm{NaScTx}$. This paper aimed to explore and characterize for the first time toxins from the ancient scorpion Tityus (Archaeotityus) mattogrossensis.
\end{abstract}

\footnotetext{
* Correspondence: osmindo@unb.br

† This work is dedicated to Prof. Dr. Carlos Alberto Schwartz (1952-2017), our mentor and friend. https://doi.org/10.1590/1678-9199-JVATITD-2021-0035

Received: 31 March 2021; Accepted: 15 June 2021; Published online: 13 December 2021
}

On-line ISSN 1678-9199 (c) The Author(s). 2021 Open Access This article is distributed under the terms of the Creative Commons Attribution 4.0 International License (http:// creativecommons.org/licenses/by/4.0/), which permits unrestricted use, distribution, and reproduction in any medium, provided you give appropriate credit to the original author(s) and the source, provide a link to the Creative Commons license, and indicate if changes were made. The Creative Commons Public Domain Dedication waiver (http://creativecommons.org/ publicdomain/zero/1.0/) applies to the data made available in this article, unless otherwise stated. 


\section{Background}

All scorpion species considered dangerous to man belong to the Buthidae family, the only family geographically distributed throughout all continents. It is estimated that there are approximately 1228 species in Buthidae belonging to approximately 80 genera, six of them with medical importance: Androctonus, Centruroides, Hottentotta, Leiurus, Parabuthus and Tityus [1]. Tityus is a neotropical scorpion genus and the most diverse in Buthidae family with more than 200 described species [2], being especially diversified in Central and South America tropical areas, only a few species occur in temperate South America [3].

Due the intrageneric morphological variation, Tityus genus is the most taxonomically confusing in Buthidae, making a taxonomic revision necessary [4]. Based on morphological characters Lourenço [5] suggested to separate Tityus into five subgenera:

- Archaeotityus proposed to gather the species currently reported to the group 'Tityus clathratus' species and scorpions from columbianus group of Kraepelin (1911), formed by small and irregularly painted forms;

- Atreus that covers species from 'Tityus asthenes' group and Cambridgei group of Kraepelin (1911), composed of large, reddish-brown to black in color specimens;

- Brazilotityus that can be distinguished from Tityus by the following characters: (i) combs much smaller than those found in Tityus species, with particularly reduced fulcers, (ii) sharp edges of the fixed and mobile fingers of the hands of the pedipalps with 10-12 / 11-13 sets of granules;

- Caribetityus created to gather some species of Tityus of Grandes Antilles, distributed in particular in the Dominican Republic and it has as its type species Caribe Tityus elii;

- Tityus that comprises species like Tityus bahiensis.

Archaeotityus includes 24 valid species distributed in the Neotropical region from Costa Rica to central Argentina. The Archaeotityus species share a small size $(20-40 \mathrm{~mm})$, general coloring reticulated on a background ranging from pale yellow to reddish and a medium to large pyramidal subaculular tubercle [6]. According to Lourenço [5], Archaeotityus constitutes the ancient group occupying a plesiomorphic position, because the variegated pigmentation and median dorsal carina strongest distal tooth are considered primitive characters and found only in the juvenile stages of Tityus species. The Tityus characterized toxins are almost totally from subgenera Atreus and Tityus species, there is scarce data about toxins produced by Archaeotityus [7].

The endemic Brazilian Cerrado scorpion Tityus (Archaeotityus) mattogrossensis (Borelli, 1901) is found in the Brazil Midwest, Bahia and north of Minas Gerais states [8]. Tityus (Archaeotityus) mattogrossensis sting is considered of small severity due to the low degree of reaction and the few recorded cases [9]. The accident with species of the subgenus Archaeotityus is considered mild and moderate, commonly presenting pain at the sting site shortly after the accident and paresthesia in the affected area. In some cases, the victims also experienced chills, dizziness, headache and vomiting $[9,10]$.

The present study aims to describe the first two Tityus (Archaeotityus) mattogrossensis toxins and their electrophysiological activity in Nav 1.3, Nav 1.6, DUM and DRG cells, enhancing knowledge on relationship of Archaeotityus with other Tityus NaScTx.

\section{Methods}

The specimens ( $\mathrm{n}=60$ ) of Tityus (Archaeotityus) mattogrossensis (Figure 1A) were collected in the municipality of Jaborandi,

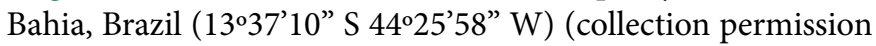
- SISBIO: 23408-1 and SISGEN A826A3A), with the help of LED-UV lanterns $(395 \mathrm{~nm})$. After collection, the animals were kept in containment boxes in vivariums of the Institute of Biology at University of Brasilia, Brazil, with adequate humidity and temperature, with water "ad libitum" and periodically fed with cockroaches.

The venom extraction was performed through an electrical stimulus (from 50 to $100 \mathrm{~V}, 300 \mathrm{~Hz}$ ) close to the telson. The venom was collected in polyethylene tubes, solubilized in $1 \mathrm{~mL}$ of deionized water and centrifuged for $10 \mathrm{~min}$ at $10,500 \mathrm{xg}$, at room temperature. The quantification of the crude venom was performed using a spectrophotometer (absorbance $280 \mathrm{~nm}$ ), assuming that an absorbance unit in a $1 \mathrm{~cm}$ quartz cuvette is equivalent to $1 \mathrm{mg} / \mathrm{mL}$ of protein concentration [11]. Then, the crude venom was vacuum dried (SPD2020 Integrated SpeedVac Concentrator, Thermo Fisher Scientific) and kept refrigerated $\left(-20^{\circ} \mathrm{C}\right)$ for further analysis.

\section{Venom purification - RP-HPLC}

Crude venom aliquots $(10 \mathrm{mg} / \mathrm{mL})$ containing $0.12 \%$ trifluoroacetic acid (TFA) were applied in a reverse phase high performance liquid chromatography system (RP-HPLC): Shimadzu Co. (Kyoto, Japan) LC10A series; equipped with SPD-M10A diode array and C18 Phenomenex Synergi Hydro-RP analytical column (4.60 x $250 \mathrm{~mm}, 4 \mu \mathrm{m}$ ) with binary solvent gradient: solvent (A) $0.12 \%$ TFA aqueous solution and solvent (B) acetonitrile solution and $0.1 \%$ TFA $(\mathrm{v} / \mathrm{v})$, with a variation from 0 to $60 \%$ of $\mathrm{B}$ in $60 \mathrm{~min}$; from 60 to $100 \%$ B in $5 \mathrm{~min} 100 \% \mathrm{~B}$ in $5 \mathrm{~min}, 100$ to $0 \% \mathrm{~B}$ in 5 min with absorbance monitoring at 216 and $280 \mathrm{~nm}$ and with a flow rate of $1 \mathrm{~mL} / \mathrm{min}$. The fractions were manually collected, vacuum dried (SPD2020 Integrated SpeedVac Concentrator, Thermo Fisher Scientific) and stored at $-20^{\circ} \mathrm{C}$.

For further analysis, F5 (Tm1) and F6 (Tm2) were submitted to other chromatographic step on RP-HPLC system using analytical column Phenomenex Luna C18 $(4.60 \times 150 \mathrm{~mm}, 3$ $\mu \mathrm{m})$, optimized gradient of acetonitrile was used: $0-25 \%$ of $B$ in $5 \mathrm{~min}$, followed by $25-35 \%$ of B for 20 minutes, $35-100 \%$ of $\mathrm{B}$ for 5 minutes and $100 \%$ of B for more 5 minutes; monitored at 216 and $280 \mathrm{~nm}$. 


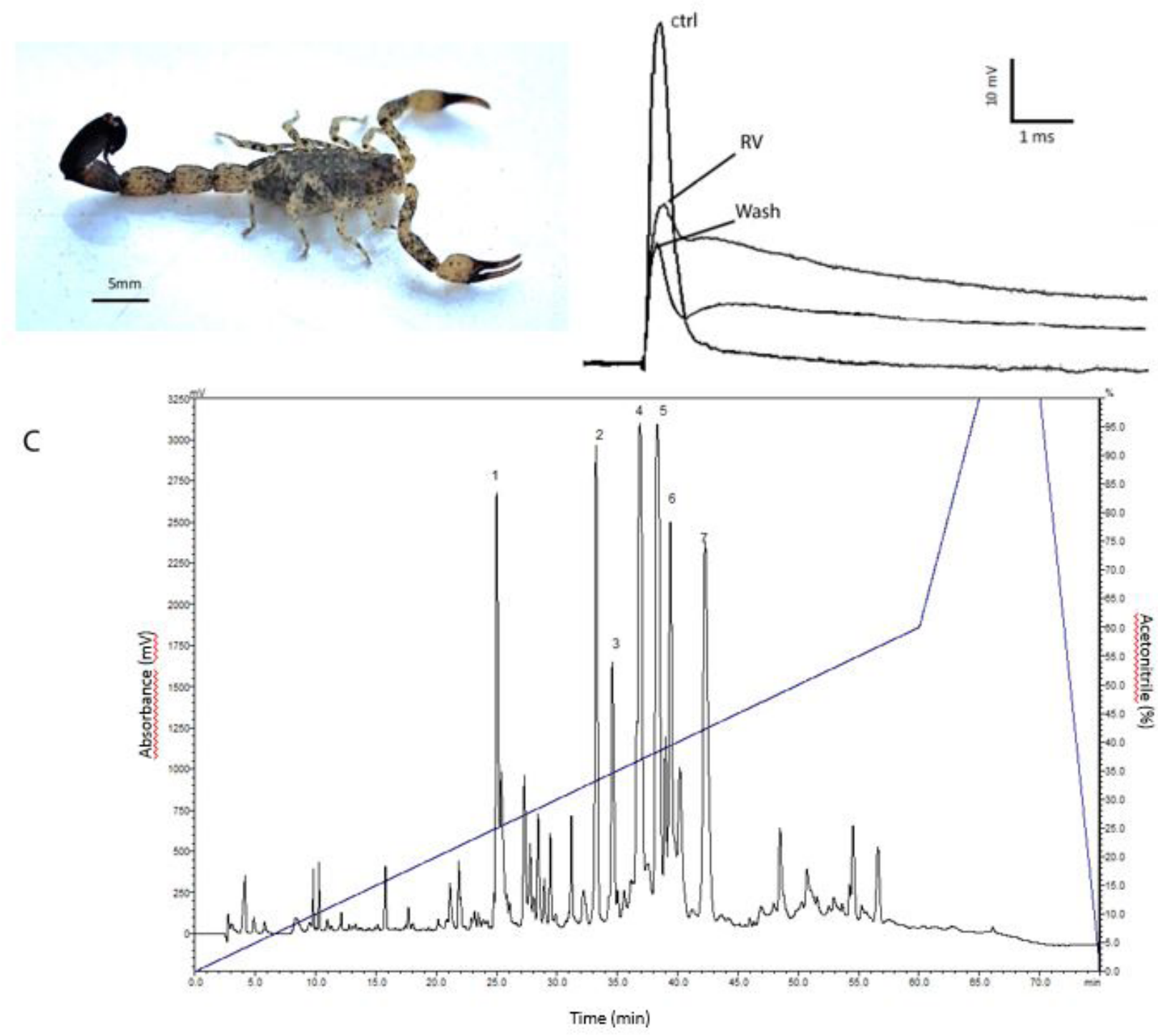

Figure 1. (A) Specimen of Tityus (Archaeotityus) mattogrossensis. Photo by Osmindo R. P. Júnior. (B) Effect of Tityus (Archaeotityus) mattogrossensis crude venom (0.754 $\mathrm{mg} / \mathrm{mL}$ ) on the action potential of the frog sciatic nerve, using the single sucrose-gap technique. Ctrl: control; RV: potential reduction after 1 minute of application of Tityus (Archaeotityus) mattogrossensis crude venom; Wash: after 10 minutes of washing, showing that the action is irreversible $(n=1)$. (C) Chromatogram of Tityus (Archaeotityus) mattogrossensis crude venom $(10 \mathrm{mg} / \mathrm{mL})$. The seven most abundant chromatographic fractions used in this work are indicated. C18 Phenomenex Synergi Hydro analytical column $(4.60 \times 250 \mathrm{~mm})$ and the fractions detected at $216 \mathrm{~nm}$, flow of $1 \mathrm{~mL} / \mathrm{min}$ and acetonitrile gradient according to the methodology described in the text.

The fractions were manually collected and quantified by calculating the detection at 216, 280 and $340 \mathrm{~nm}$ from the NanoVue spectrophotometer (GE Healthcare, Sweden) using the protein methodology provided by the manufacturer and kept dry at $-20^{\circ} \mathrm{C}$ for later analysis.

\section{Mass spectrometry}

MALDI-TOF/MS analyses were performed on MALDI-TOF system mass spectrometers (ULTRAFLEX III and AUTOFLEX
SPEED, Bruker Daltonics, Billerica, MA, USA) in positive linear and reflected modes. The 7 more abundant fractions (F1 to 7) from the crude venom HPLC purification were applied to a MALDI-TOF analysis plate followed by the addition of saturated solution of a-cyano-4-hydroxycinnamic acid matrix (HCCA), the following calibrators were used: Peptide calibration standard II for low mass and Protein calibration I for high mass both from the Bruker Daltonics Inc. Nitrogen laser was used at an intensity of 20 to $40 \%$. 
The monoisotopic masses of high molecular weight peptides were elucidated with the use of the ionization mass spectrometer by Electrospray coupled to a quadrupole-TOF system (MicrOTOFQII, Bruker Daltonics, Germany), operated in positive mode. The samples were dissolved in a solvent with $50 \%$ acetonitrile, $47.3 \%$ deionized water and $2.6 \%$ formic acid and injected into the system by a $180 \mu \mathrm{L} / \mathrm{min}$ continuous flow pump.

\section{De novo sequencing and phylogenetic tree construction}

For the de novo sequencing F5 (Tm1) and F6 (Tm2) were analysed with and without trypsin digestion: spectra of intact proteins were acquired by using the In Source Decay (ISD) method using the reducing matrix 1,5-diaminonaphthalene (DAN), which mainly results on $c$ - and $z$ - ions [12], bovine serum albumin (BSA) as calibrator was used.

The second technique used trypsin digestion: the peptides were reduced by dithiothreitol-DTT (25 mM DTT in $100 \mathrm{mM}$ $\mathrm{NH}_{4} \mathrm{HCO}_{3}$ ) for $1 \mathrm{~h}$ in continuous agitation at $60^{\circ} \mathrm{C}$ and alkylated by Iodoacetamide ( $25 \mathrm{mM}$ Iodoacetamide also diluted in solution of $100 \mathrm{mM} \mathrm{NH}_{4} \mathrm{HCO}_{3}$ ), for $40 \mathrm{~min}$ with continuous agitation at $37^{\circ} \mathrm{C}$. The samples were digested in $50 \mathrm{mM}$ immobilized Trypsin (TPKC Treated- Thermo Fisher Scientific) in $100 \mathrm{mM}$ $\mathrm{NH}_{4} \mathrm{HCO}_{3}$ buffer, incubated at $37^{\circ} \mathrm{C}$ from 2 to $4 \mathrm{~h}$ [12].

The tryptic fragments were analysed in MALDI-TOF/MS and fragmented using LIFT mode. The sequences were interpreted using Flex Analysis 3.3 software.

BLAST suite (http://blast.ncbi.nlm.nih.gov/Blast.cgi?PAGE =Proteins) was used for sequence similarity search in NCBI protein database Clustal Omega (https://www.ebi.ac.uk/Tools/ $\mathrm{msa} / \mathrm{clustalo} /$ ) was used to alignment the mature toxins sequences obtained with Tm1 and Tm2.

The Phylogeny tree was performed by Simple Phylogeny tool (https://www.ebi.ac.uk/Tools/phylogeny/simple_phylogeny/) after the sequences alignment. Conditions: Tree Format Default, Distance Correction Off, Exclude Gaps Off, Clustering Method Neighbour-Joining and P.I.M. Off.

\section{Electrophysiology}

\section{Single sucrose gap}

The activity of Tityus (Archaeotityus) mattogrossensis crude venom $(0.754 \mathrm{mg} / \mathrm{mL})$ or RP-HPLC fractions $(0.4 \mu \mathrm{g} / \mathrm{mL}$ of protein) were tested on the action potential of the frog sciatic nerve (Lithobates catesbeianus), an adaptation of the "single sucrose-gap" technique described in [13]. This work was approved by the Animal Use Ethics Committee of University of Brasilia, number $124645 / 2011$.

The frog was euthanized, the sciatic nerve was removed and the connective tissue surrounding it was carefully removed. The nerve was placed through 5 cell chambers, mechanically and electrically isolated with vaseline seals. The first two chambers were used for supramaximal stimulation, pulses from 6 to 7 V, $25 \mathrm{~ms}$, generated by the stimulator S8 - Grass Instruments.
In the third, was the assay chamber, which $350 \mu \mathrm{L}$ of the venom fraction were applied, after the assay this chamber also can be constantly washed by an infusion system. In the fourth chamber a $216 \mathrm{mM}$ sucrose solution was placed and constantly renewed with an infusion system. With the exception of chamber 4, all other chambers were filled with saline solution for amphibians - Ringer (111 mM NaCl, $1.9 \mathrm{mM} \mathrm{KCl,} 2.4 \mathrm{mM} \mathrm{NaHCO}_{3}$ and 1.1 $\mathrm{mM} \mathrm{CaCl}_{2}$ ) keeping the nerve submerged. Action potentials were captured in chambers 3 and 5 by Ag- $\mathrm{Cl}$ electrodes connected to a high impedance DC differential amplifier with a 50fold gain coupled to a Tektronix TDS 360 digital oscilloscope (Tektronix, USA). Records were made every 5 min after the sample application, for a total of $40 \mathrm{~min}$, and every 5 minutes after the start of the washing of the assay chamber, for a total of $30 \mathrm{~min}$. These records were compared with the control record obtained before applying the sample. The tests took place at room temperature and the samples to be were resuspended 350 $\mu \mathrm{L}$ of Ringer's solution [14].

\section{Whole cell patch clamp}

The micropipettes were made from glass capillaries using a drawing board (model PP-830, Narishige, Japan) and were filled with the internal solution according to each cell type. The records of ionic currents were made with 1-3 M' $\Omega$ resistance, in an EPC 9- Patch Clamp Amplifier (HEKA, Germany). Current responses were recorded using the PatchMaster, HEKA software and analyzed with Sigma Plot 10.0 software.

The Tm 1 and $\mathrm{Tm} 2$ peptides isolated from the T. (Archaeotityus) mattogrossensis venom were dissolved in a specific external solution for each tested cell ( $1 \mu \mathrm{M}$ of each peptide) and microperfused throughout the experiment using a micropipette placed close to the recorded cell. The experiments were carried out at room temperature $\left(25 \pm 2{ }^{\circ} \mathrm{C}\right)$.

The Patch Clamp was recorded in four different cell types: immortalized HEK293 cells (human embryo kidney) that express only Nav 1.3 channels and HEK293 cells that express only Nav 1.6; DRG cells (rat Dorsal Root Ganglion); and DUM cells (Dorsal Unpaired Median from cockroach).

\section{HEK293 cells}

HEK cells were cultured in DMEM medium with $4.5 \mathrm{~g} / \mathrm{L}$ glucose, $10 \%$ fetal bovine serum and $1 \%$ antibiotic (5000 units of penicillin and $5 \mathrm{mg}$ of streptomycin $/ \mathrm{mL}$ ) and incubated at $37^{\circ} \mathrm{C}$ in an atmosphere of $5 \% \mathrm{CO}_{2}$. The cells were bathed with the external solution (140 mM NaCl, $2 \mathrm{mM} \mathrm{CaCl}_{2}, 1 \mathrm{mM} \mathrm{MgCl}_{2}, 15 \mathrm{mM}$ Glucose and $10 \mathrm{mM}$ HEPES, $\mathrm{pH}$ 7.4) and the micropipette filled with the internal solution ( $130 \mathrm{mM} \mathrm{CsCl}, 1 \mathrm{mM} \mathrm{MgCl}, 10 \mathrm{mM}$ HEPES, 10 mM EGTA, 5 mM NaCl, pH 7.2).

Two electrophysiological protocols were used, the first, called "test 0 ", the cell was maintained at the holding potential of -80 $\mathrm{mV}$, then a pulse of $-120 \mathrm{mV}$ with a duration of $100 \mathrm{~ms}$ was applied, so that all sodium channels were in the closed state, and just after a test pulse of $0 \mathrm{mV}$ for $50 \mathrm{~ms}$. The second, a -120 $\mathrm{mV}$ prepulse was applied with a duration of $100 \mathrm{~ms}$ and starting 
from the potential of $-80 \mathrm{mV}$ in increments of $10 \mathrm{mV}$ (up to +80 $\mathrm{mV}$ ) for $50 \mathrm{~ms}$, to obtain a current/voltage ratio.

To complement the analysis of $\operatorname{Tm} 1$ and $\operatorname{Tm} 2$ activity on the Nav channels, the same " 0 test" and current vs voltage protocols were performed, but with a depolarizing pulse of $+50 \mathrm{mV}$ for 1 $\mathrm{ms}$ before applying the $0 \mathrm{mV}$ pulse as in the previous protocol.

\section{DRG cells}

To isolate rat dorsal root ganglion cells (DRG), a male Wistar rat (approximately $250 \mathrm{~g}$ ) was beheaded by guillotining and all dorsal root ganglia were removed and placed in $0.9 \% \mathrm{NaCl}$ solution. Subsequently, they went through two enzymatic processes for cell dissociation: in the first, the ganglia were placed for $20 \mathrm{~min}$ at $37^{\circ} \mathrm{C}$ in a solution of $3 \mathrm{mg}$ papain and 2 crystals of cysteine diluted in $3 \mathrm{~mL}$ of mammalian ringer without $\mathrm{Ca}^{2+}$ and $\mathrm{Mg}^{2+}$ $(140 \mathrm{mM} \mathrm{NaCl}, 2.5 \mathrm{mM} \mathrm{KCl}, 10 \mathrm{mM}$ HEPES, $7.5 \mathrm{mM}$ glucose, $\mathrm{pH}$ 7.4), subsequently centrifuged at $800 \mathrm{xg}$ for $1 \mathrm{~min}$ and the supernatant discarded. The same procedure was carried out in the second enzymatic process, however with $7.5 \mathrm{mg}$ type II collagenase enzyme from Clostridium histolyticum diluted in 3 $\mathrm{mL}$ of ringer. The cells were washed and mechanically crushed in HAM F-12 culture medium, $1 \%$ antibiotic (5000 units of penicillin and $5 \mathrm{mg}$ streptomycin $/ \mathrm{mL}$ ), plated and, after $2 \mathrm{~h}$, fed with culture medium L-15, $0.5 \%$ antibiotic (5000 units of penicillin and $5 \mathrm{mg}$ of streptomycin $/ \mathrm{mL}$ ), $50 \%$ glucose and $1.4 \%$ of HEPES. The cells were kept at room temperature for up to $72 \mathrm{~h}$.

Upon registration of sodium currents, cells were bathed with a combination of two external solutions: $\mathrm{NaCl}$ solution $(115 \mathrm{mM}$ $\mathrm{NaCl}, 5 \mathrm{mM} \mathrm{KCl}, 2 \mathrm{mM} \mathrm{CaCl}_{2}, 1 \mathrm{mM} \mathrm{MgCl}$, $10 \mathrm{mM}$ HEPES, 20 mM TEA-Cl, $0.2 \mathrm{mM} \mathrm{CdCl}_{2}, 0.2 \mathrm{mM} \mathrm{NiCl}_{2}$ and $5 \mathrm{mM}$ glucose, $\mathrm{pH}$ 7.4) and Choline chloride solution (115 mM ChoCl, $5 \mathrm{mM}$ $\mathrm{KCl}, 2 \mathrm{mM} \mathrm{CaCl}, 1 \mathrm{mM} \mathrm{MgCl}, 10 \mathrm{mM}$ HEPES, $20 \mathrm{mM}$ TEA$\mathrm{Cl}, 0.2 \mathrm{mM} \mathrm{CdCl}_{2}, 0.2 \mathrm{mM} \mathrm{NiCl}_{2}$ and $5 \mathrm{mM}$ glucose, $\mathrm{pH}$ 7.4). The solution for filling the micropipettes was $100 \mathrm{mM} \mathrm{CsF}, 20$ $\mathrm{mM} \mathrm{NaCl}, 10 \mathrm{mM}$ HEPES, $11 \mathrm{mM}$ EGTA, $10 \mathrm{mM}$ TEA-Cl and $5 \mathrm{mM} \mathrm{MgCl}, \mathrm{pH}$ 7.2. Potassium currents were blocked with the presence of $\mathrm{Cs}^{+}$in internal solution and TEA in the external and internal solutions. $\mathrm{Ca}^{2+}$ currents were blocked by $\mathrm{Cd}^{2+}$ and $\mathrm{Ni}^{2+}$ in external solutions.

Two electrophysiological protocols were used, the first, "test 0 ", the cell was maintained in a "potential holding" of $-80 \mathrm{mV}$, then a pulse of $-120 \mathrm{mV}$ was applied with a duration of $100 \mathrm{~ms}$, so that all channels for sodium were close, and just after a test pulse of $-20 \mathrm{mV}$ for $100 \mathrm{~ms}$. The second protocol, a $-100 \mathrm{mV}$ prepulse was applied with a duration of $100 \mathrm{~ms}$ and starting from the potential of $-120 \mathrm{mV}$ in increments of $10 \mathrm{mV}$ (up to $+30 \mathrm{mV}$ ) per $100 \mathrm{~ms}$, to obtain the current/voltage ratio.

\section{DUM cells}

The DUM cells were isolated from cockroaches Periplaneta americana. Ten individuals were euthanized by freezing and the last ganglia from the abdominal nerve cord removed for dissection.
The ganglia were placed in saline solution $(200 \mathrm{mM} \mathrm{NaCl} ; 3.1$ $\mathrm{mM} \mathrm{KCl} ; 5 \mathrm{mM} \mathrm{CaCl} ; 4 \mathrm{mM} \mathrm{MgCl} ; 10 \mathrm{mM}$ HEPES; $50 \mathrm{mM}$ sucrose; $\mathrm{pH}$ 7.4) containing $3 \mathrm{mg}$ of collagenase (type 1A from Clostridium histolyticum), for $45 \mathrm{~min}$ at $37^{\circ} \mathrm{C}$.

The solution was centrifuged for $25 \mathrm{~s}$ at $5000 \mathrm{rpm}$ and the supernatant was discarded. The enzyme was washed 3 times with $3 \mathrm{~mL} \mathrm{SSAS}$ medium (saline, $2 \%$ fetal bovine serum and $1 \%$ antibiotic - 5000 units of penicillin and $5 \mathrm{mg}$ of streptomycin/ $\mathrm{mL}$ ). Finally, the cells underwent mechanical grinding, plated and fed, after $2 \mathrm{~h}$, with the same medium. The cells were kept at room temperature for up to $24 \mathrm{~h}$.

The cells were bathed with the external solution $100 \mathrm{mM} \mathrm{NaCl}$, $100 \mathrm{mM}$ TEA-Cl, $3.1 \mathrm{mM} \mathrm{KCl}, 0.05 \mathrm{mM} \mathrm{CdCl}_{2}, 2 \mathrm{mM} \mathrm{CaCl}_{2}$, $7 \mathrm{mM} \mathrm{MgCl}_{2}, 4 \mathrm{mM}$ aminopyridine and $20 \mathrm{mM}$ HEPES, $\mathrm{pH}$ 7.3. The solution for filling the micropipettes was $15 \mathrm{mM} \mathrm{NaCl}$, $80 \mathrm{mM} \mathrm{CsCl}, 5 \mathrm{mM}$ EGTA, $10 \mathrm{mM}$ HEPES, $2 \mathrm{mM}$ ATP- $\mathrm{Mg}_{2}$, $1 \mathrm{mM} \mathrm{MgCl}, \mathrm{pH}$ 7.4.

The two electrophysiological protocols used for the DUM cell were: In the first, "test 0 ", the cell was maintained at a potential holding potential of $-90 \mathrm{mV}$, then a pulse of $-120 \mathrm{mV}$ with a duration of $100 \mathrm{~ms}$ was applied, so that the sodium channels close, and just after a test pulse of $0 \mathrm{mV}$ for $50 \mathrm{~ms}$. In the second, to obtain a current/voltage ratio, a $-100 \mathrm{mV}$ prepulse was applied with a duration of $100 \mathrm{~ms}$ and starting from the potential of $-120 \mathrm{mV}$ in increments of $10 \mathrm{mV}$ (up to $+30 \mathrm{mV}$ ) per $100 \mathrm{~ms}$.

\section{Results}

The single sucrose gap was performed with the crude venom $(0.754 \mathrm{mg} / \mathrm{mL})$, effects are evidenced by the delay in repolarization and the reduction in the amplitude of the compound action potential, when compared with the control $(\mathrm{n}=1)$ (Figure 1B). Purification of the crude venom by RP-HPLC (C18 analytical column Phenomenex Synergi Hydro 250 x $4.60 \mathrm{~mm}$, detection at $216 \mathrm{~nm}$ ) presented 67 fractions, with 7 predominant fractions (Figure 1C).

In order to find the neuroactive peptides from the $T$. (Archaeotityus) mattogrossensis venom, the 7 most abundant chromatographic fractions highlighted in Figure $1 \mathrm{C}$ were tested, individually in single sucrose gap $(\mathrm{n}=1)$, as well as the molecular masses present in these fractions were elucidated by MALDITOF mass spectrometry.

F2 caused a delay in repolarization of the action potential, and fractions 5-7 caused a reduction in amplitude of the action potential (Figure 2).

F5 and F6 (0.4 $\mu \mathrm{g} / \mathrm{mL}$ of total protein) reduced $40 \%$ and $62.5 \%$ of the amplitude of action potential in a frog nerve in single sucrose gap (Figure 2), respectively, which is characteristic of NaScTx. F5 and F6 were chosen for further characterization due to abundance in venom, and renamed as $\operatorname{Tm} 1$ and $\mathrm{Tm} 2$ respectively.

The $\mathrm{Tm} 1$ after further purification steps (Figure $3 \mathrm{~A}$ ) presented a single component with an average mass of 7312.0 Da in MALDITOF in linear mode (Figure $3 \mathrm{~B}$ ). The de novo sequencing by ISD revealed only 8 amino acid residues (Additional file 1). The 


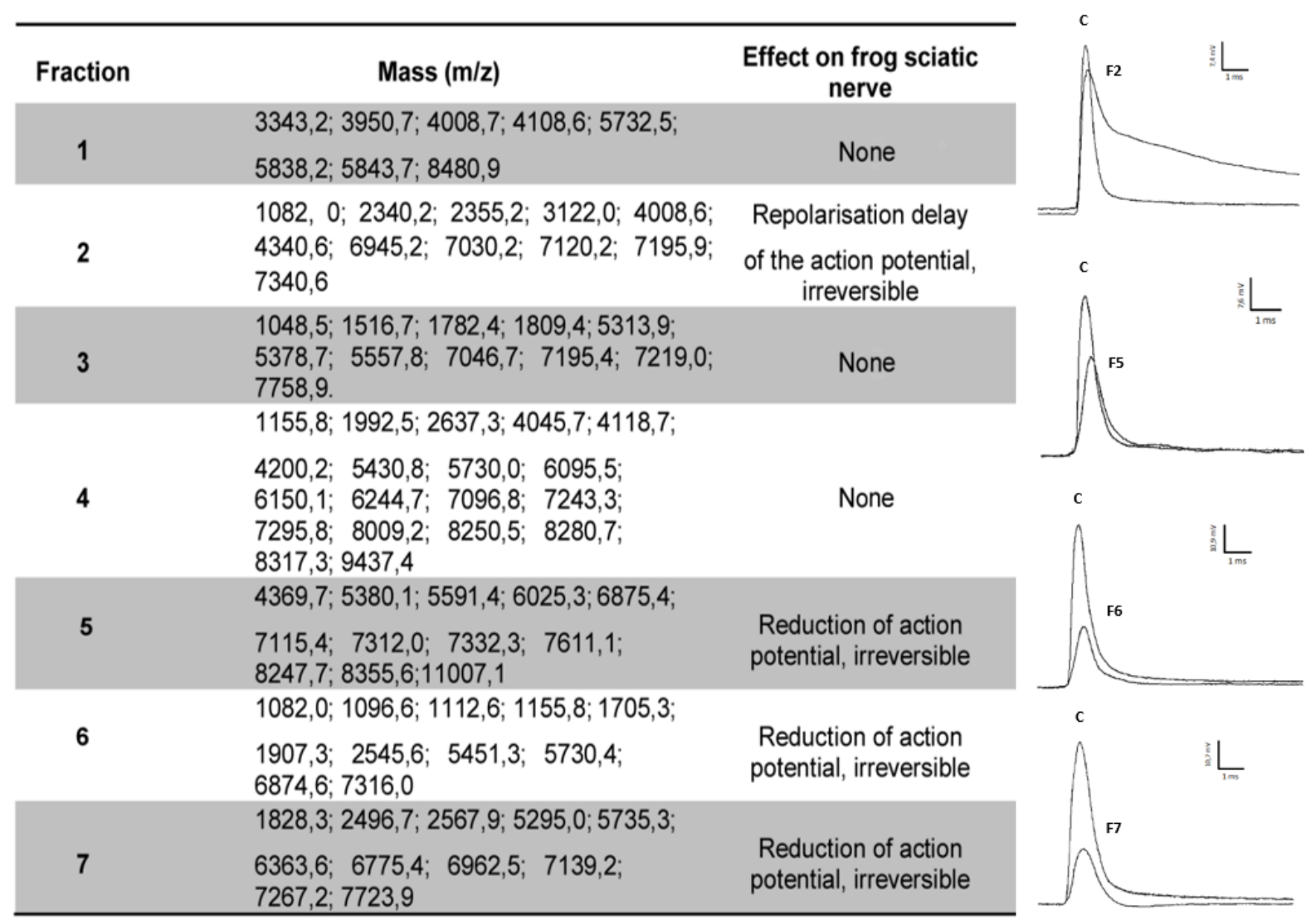

Figure 2. On the left: the summary of the seven most abundant fractions in Tityus (Archaeotityus) mattogrossensis venom, masses and the effect on frog sciatic nerve. On the right: electrophysiological analysis $(n=1)$ of $F 2, F 5, F 6$ and F7 $(0.4 \mu \mathrm{g} / \mathrm{mL}$ of total protein, each) in sucrose gap in frog sciatic nerve, after 40 min of fraction application. F5 (Tm1) shows a 40\% reduction in the amplitude of action potential and F6 ( $\operatorname{Tm} 2$ ) 62.5\% reduction in the amplitude of action potential. C: control test.

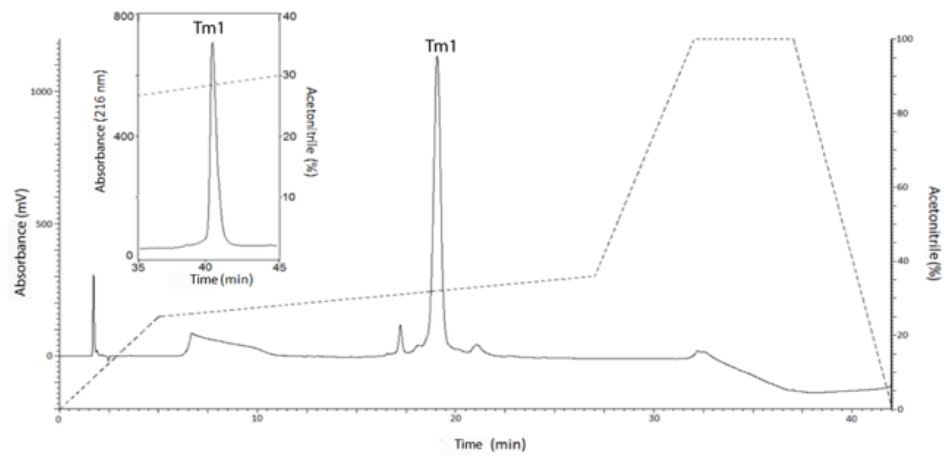

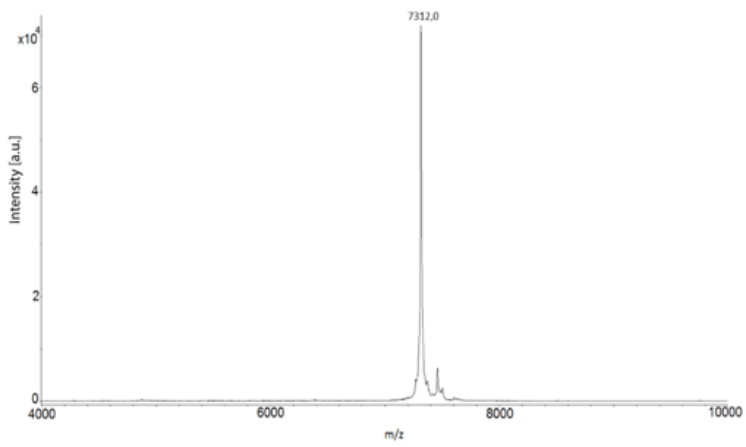

C

\begin{tabular}{|c|c|}
\hline Tm1 & $\cdots-$ DHVKGCKYSCFIRPWGFCDRYCKTNMSAASGYCAWPACYCYGVPKNEPVWDYDTN KC - \\
\hline To12 & KEGYPMDHEGCKFSCFIRPSGFCERYCKTHLSASTGYCAWPACYCYGVPANQKVWDYYNN KCGK \\
\hline Ts2 & KEGYAMDHEGCKFSCFIRPAGFCDGYCKTHLKASSGYCAWPACYCYGVPDHIKVWDYATN KC - - \\
\hline Tb2-II & KEGYAMDHEGCKFSCFIRPSGFCDGYCKTHLKASSGYCAWPACYCYGVPSNIKVWDYATN KC - - \\
\hline Tf2 & $\begin{array}{l}\text { KEGYAMDHEGCKFSCFIRPSGFCDGYCKTHLKASSGYCAWPACYCYGVPSNIKVWDYATN KCGK } \\
.: * * *: * * * * * * * * *: * * * *::^{*}::^{* * * * * * * * * * * * * *:} ; * * * ; * * *\end{array}$ \\
\hline
\end{tabular}

Figure 3. (A) Second step of purification of Tm 1 in RP-HPLC analytical column Luna Phenomenex $(4.60 \times 150 \mathrm{~mm}, 3 \mu \mathrm{m})$. (B) Mass spectrometry MALDI-TOF in positive linear mode, showing the relative degree of purity and the average mass of the peptide. (C) Clustal Omega Tm1 sequence alignment with high similarity scorpion toxins sequences found in BLAST analysis. Cysteine residues are highlighted in gray. 
fragmentation analysis (MALDI-TOF MS/MS) of the tryptic digested peptides by using LIFT mode allowed to infer a partial sequence of 57 amino acid residues (Additional file 2).

The overlapping of the tryptic fragments and the small sequence obtained by ISD resulted in the following partial sequence for Tm1: DHVK/QGCK/QYSCFI/LRPWGFCDRYCK/ QTNMSAASGYCAWPACYCYGVPKNEPVWDYDTNKC. The calculation of cysteine residues performed after the reduction and alkylation of the peptide, showed the presence of $8 \mathrm{~S}$-carboxyamidomethylated cysteine residues. With the methodologies used it was not possible to elucidate the $\mathrm{N}$-terminal sequence of Tm1.

Tm1 sequence were submitted to NCBI protein database obtaining, 75\% similarity with Tityus bahiensis Tb2-II toxin
(P60276), 75\% with Tityus fasciolatus Tf2 (C0HJM9), 74\% with Tityus obscurus To12 (H1ZZI1), and 74\% Tityus serrulatus Ts2 toxin (P68410). The mature toxins were alignment done using the Clustal Omega (Figure 3C).

The sequence and alignment suggest that Tm1 is a NaScTx, however, in order to know the real activity of this neurotoxic peptide, electrophysiological tests were performed with 4 types of neuronal cells in a patch clamp: immortalized HEK293 Nav 1.3 and HEK293 Nav 1.6, DRG and DUM.

The electrophysiological results obtained with Tm1 $(1 \mu \mathrm{M})$ showed a sodium current reduction activity, in test protocol "test 0 ", of $71.5 \%(\mathrm{n}=1)$ in Nav 1.3 channels (Figure $4 \mathrm{~A})$ and $63.3 \pm 7 \%(\mathrm{n}=3)$ reduction in Nav 1.6 (Figure $4 \mathrm{~B}) . \operatorname{Tm} 1(1 \mu \mathrm{M})$ also inhibited the sodium currents in DRG cells in $13.2 \%(n=2)$
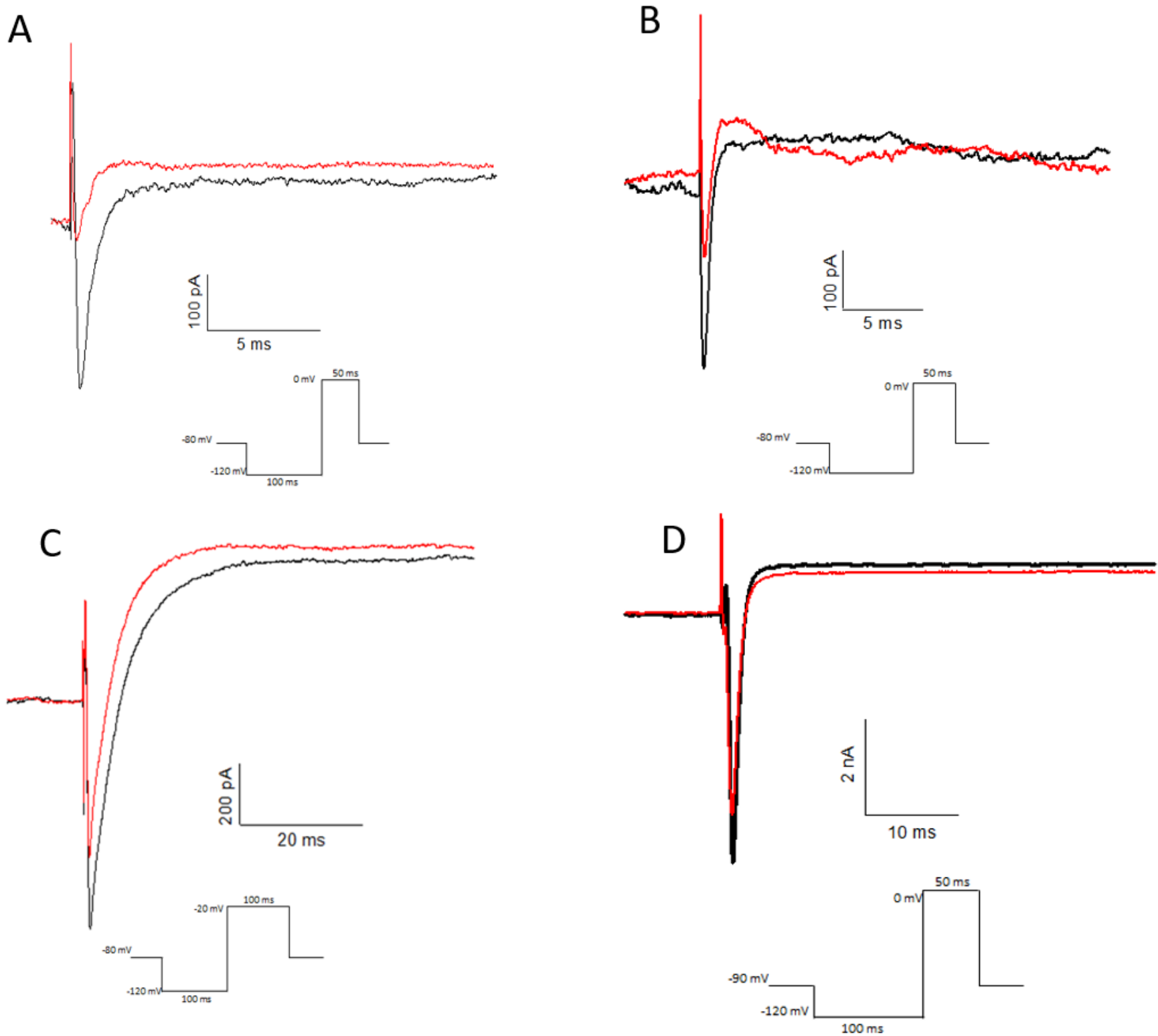

Figure 4. $\operatorname{Tm} 1(1 \mu \mathrm{M})$ toxin activity (red) compared to the control (black) in whole-cell patch clamp with: (A) HEK293 Nav 1.3 , showing a $71.5 \%(\mathrm{n}=1)$ reduction in current; (B) HEK293 Nav 1.6 showing a $63.3 \pm 7 \%(n=3)$ reduction in current; (C) DRG showing a $13.2 \pm 7 \%(n=2)$ reduction in current; (D) DUM showing a $35 \pm 4.1 \%(n=5)$ reduction in current. 
(Figure 4C). And in DUM cells, $\operatorname{Tm} 1(1 \mu \mathrm{M})$ showed a considerable effect of $35 \pm 4.1 \%(n=5)$ of sodium current reduction (Figure 4D). In all assays the action of Tm1 was irreversible. In measuring voltage vs current in HEK298 Nav 1.6 cells, the shift to more negative potentials was not observed, which indicates that Tm1 is not a $\beta-\mathrm{NaScTx}$ (Additional file 3).

The second purification step of $\operatorname{Tm} 2$ is presented in Figure $5 \mathrm{~A}$. The degree of purity and the average mass of 7112.8 Da was obtained by MALDI-TOF/MS in the positive linear mode (Figure 5B). And the monoisotopic mass of 7108.0Da was defined by MicrOTofQII, and calculated using the Bruker Compass software.

Tm2 peptide was also sequenced in two stages: 37 amino acid residues were obtained by ISD (Additional file 4); and four tryptic fragments by LIFT mode (Additional file 5).

The calculation of cysteines performed after the reduction and alkylation of the peptide, showed the presence of $8 \mathrm{~S}$-carboxyam idomethylated cysteine residues. The partial sequence obtained for Tm2 was K/QEGYPTPHEGCKFSCFI/LRPWGFCDHYCKI/ LHI/LSK/QGSGYCAWPACYCYGVPDNEPVWNYATNKC.

Tm 2 sequence were submitted to BLAST database obtaining 75\% similarity with Tityus bahiensis Tb2-II toxin (P60276), Tityus fasciolatus Tf2 (C0HJM9), Tityus serrulatus Ts2 (P68410); and $71 \%$ similarity with Tityus obscurus To12 (H1ZZI1) (Figure 5C).

A

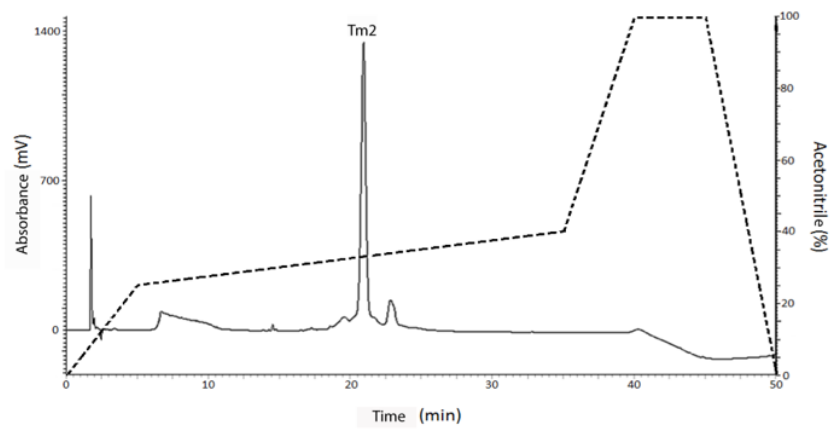

C
As $\operatorname{Tm} 2$ sequence has a high identity ( $>75 \%)$ with $\mathrm{NaScTx}$, this peptide was also submitted to patch clamp tests were performed with HEK298 Nav 1.3 and Nav 1.6, and DRG cell types. The DUM test was not performed.

Tm2 toxin $(1 \mu \mathrm{M})$ showed partially reversible activity, reducing $35.81 \pm 10.2 \%(n=5)$ of the sodium current in HEK298 Nav 1.3 cells (Figure 6A). The activity was intensified by applied the depolarizing prepulse of $+50 \mathrm{mV}$, which became an inhibition of $95.15 \pm 3.65 \%(n=2)$ (Figure $6 \mathrm{~B})$. Tm2 $(1 \mu \mathrm{M})$ showed the activity of reducing the sodium current by $25 \%$ activity in DRG cells which (Figure 6C). Tm2 showed no activity in HEK298 Nav 1.6 cells (data not shown).

In measuring voltage vs current in HEK298 Nav 1.3 cells, there were no shift to more negative potentials (Additional file 6), and the intensification of the action of Tm 2 by the pre-pulse indicates $\operatorname{Tm} 2$ is a $\alpha-\mathrm{NaScTx}$.

A phylogenetic analysis was performed to investigate the phylogenetic relationships of Tm1 and Tm2 from Tityus (Archaeotityus) mattogrossensis toxins with T. (Archaeotityus) clathratus and other Tityus NaScTxs. Figure 7 shows a consensus tree obtained after Clustal Omega alignment. Tityus (Archaeotityus) mattogrossensis clade is placed between T. (Archaeotityus) clathratus and Tityus subgenus.

B

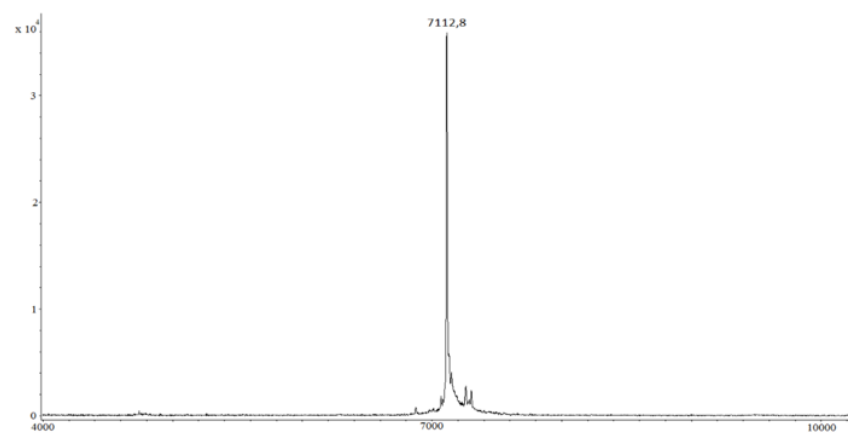

$\begin{array}{lll}\text { Tm2 } & \text { KEGYPTPHEGCKFSCFIRPWGFCDHYCKIHISKGSGYCAWPACYCYGVPDNEPVWNYATN KC- - } & 62 \\ \text { T012 } & \text { KEGYPMDHEGCKFSCFIRPSGFCERYCKTHLSASTGYCAWPACYCYGVPANQKVWDYYNN KCGK } & 64 \\ \text { Ts2 } & \text { KEGYAMDHEGCKFSCFIRPAGFCDGYCKTHLKASSGYCAWPACYCYGVPDHIKVWDYATN KC- - } & 62 \\ \text { Tb2-II } & \text { KEGYAMDHEGCKFSCFIRPSGFCDGYCKTHLKASSGYCAWPACYCYGVPSNIKVWDYATN KC- - } & 62 \\ \text { Tf2 } & \text { KEGYAMDHEGCKFSCFIRPSGFCDGYCKTHLKASSGYCAWPACYCYGVPSNIKVWDYATN KCGK } & 64 \\ & * * * * * * * * * * * * * * * * * * * * * * . . * * * * * * * * * * * *: * * * * . * * * & \end{array}$

Figure 5. (A) Second step of purification of Tm2 in RP-HPLC analytical column Luna Phenomenex Luna C18 $(4.60 \times 150 \mathrm{~mm}, 3 \mu \mathrm{m}) \mathrm{detection}$ at $216 \mathrm{~nm}$, flow of $1 \mathrm{~mL} / \mathrm{min}$, optimized gradient of acetonitrile (dotted line). (B) Mass spectrometry (MALDI-TOF/MS) of Tm2, showing the degree of purity and the average mass. (C) Alignment of the $\operatorname{Tm} 2$ sequence with the high identity sequences of other scorpion toxins present in the database. Cysteine residues are highlighted in gray. 

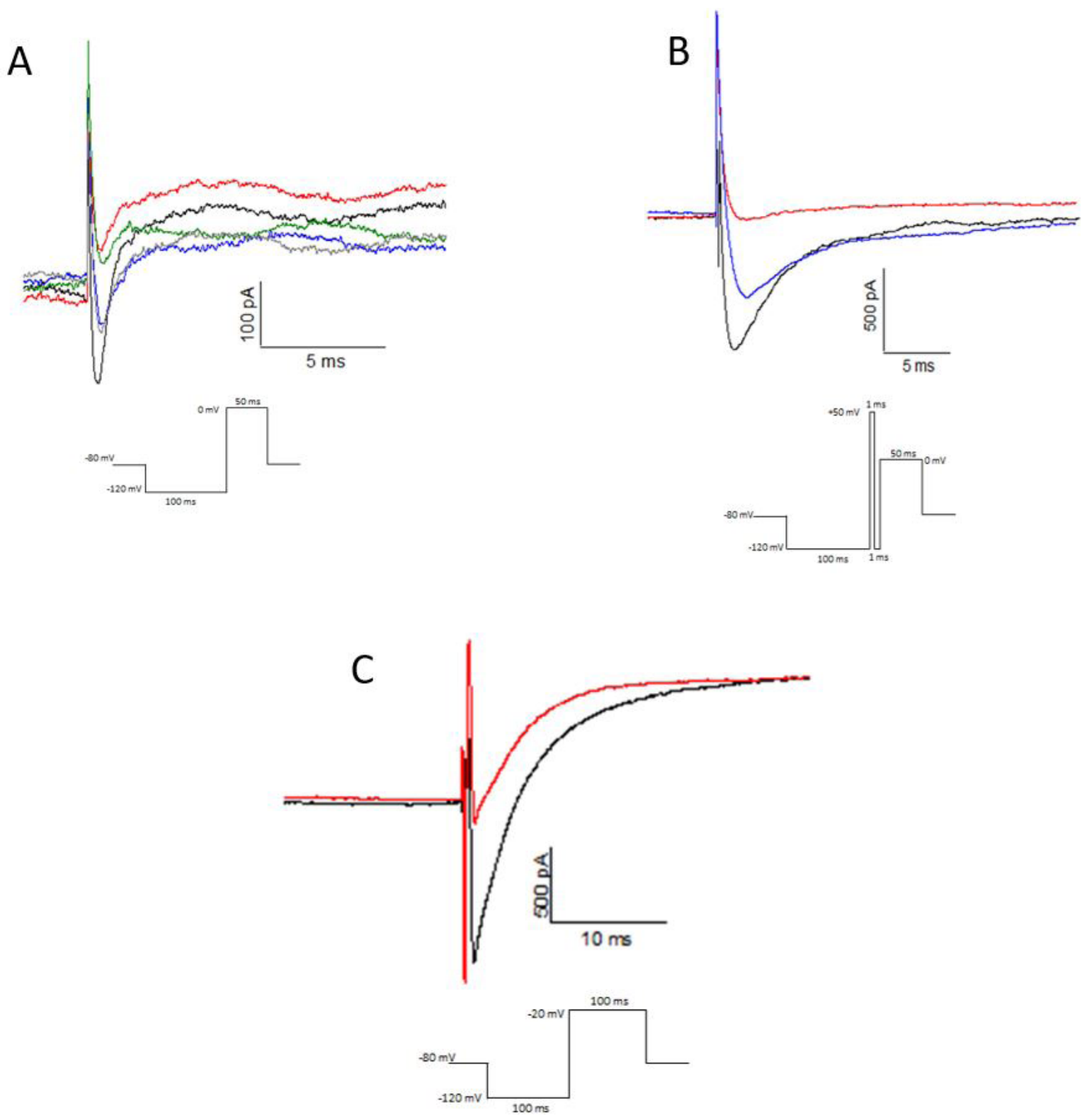

Figure 6. Tm2 $(1 \mu \mathrm{M})$ toxin activity (red) compared to the control (black) in whole-cell patch clamp with: (A) HEK293 Nav 1.3 , showing $35.81 \pm 10.2 \%(n=5)$ reduction in current partial washing (blue), Tm2 $(1 \mu \mathrm{M})$ reperfused (green) and washed (gray); (B) HEK293 Nav 1.3 cell, in depolarizing prepulse $+50 \mathrm{mV}$ for $1 \mathrm{~ms}$ protocol, showing $95.15 \pm 3.65 \%(n=2)$ reduction in current, partial washing (blue); (C) DRG showing $25 \%(n=1)$, reduction in current.
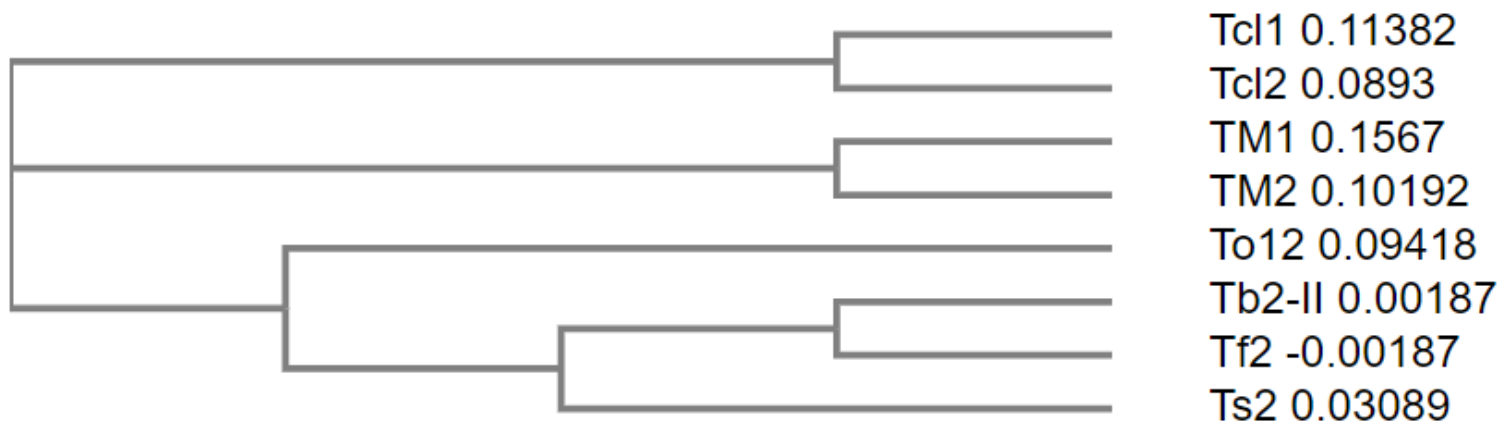

Figure 7. Phylogenetic tree obtained from Tm1 and Tm2 from Tityus (Archaeotityus) mattogrossensis isolated in this work, and Tcl1 Tityus (Archaeotityus) clathratus (J9PJ66) and Tcl2 Tityus (Archaeotityus) clathratus (J9PIJ6), Tityus bahiensis Tb2-II toxin (P60276), Tityus fasciolatus Tf2 (C0HJM9), Tityus serrulatus Ts2 (P68410); Tityus obscurus To12 (H1ZZI1). CLUSTAL Omega multiple sequence alignments is presented in Additional file 7. 


\section{Discussion}

Tityus (Archaeotityus) mattogrossensis crude venom showed to be a complex mixture with 67 fractions separated in RP-HPLC, also the crude venom promoted a delay in repolarisation and the reduction in the amplitude of the compound action potential.

The peptide sequences identified in the present work, Tm1 and Tm2, showed high identity with other NaScTxs described from scorpions of the subgenus Tityus. Tm1 toxin showed 75\% similarity with Tb2-II toxin and Tf2; and 74\% similarity with Ts2 and To12, respectively.

Tm2 peptide sequence showed $75 \%$ similarity with Tb2-II, Tf 2 and Ts2 and also presented 71\% similarity with To12.

Pimenta and collaborators (2001) [15] described the Tityus bahiensis Tb2-II (P60276) activity in mammals and in insects. Tityus serrulatus Ts2 (P68410) is a a-NaScTx and inhibits the inactivation of the activated channels, thereby blocking neuronal transmission [16]. It has been shown the specificity and selectivity of Ts2 for some mammalian sodium channels inhibiting rapid inactivation of $\mathrm{Na}_{\mathrm{v}} 1.2, \mathrm{Na}_{\mathrm{v}} 1.3, \mathrm{Na}_{\mathrm{v}} 1.5, \mathrm{Na}_{\mathrm{v}} 1.6$ and $\mathrm{Na}_{\mathrm{v}} 1.7$, but does not affect $\mathrm{Na}_{\mathrm{v}} 1.4, \mathrm{Na}_{\mathrm{v}} 1.8$ or the insect sodium channel (Drosophila melanogaster sodium channel - DmNa 1 ) [16].

Tityus fasciolatus Tf2 (COHJM9) also have a similar sequence to Tb2-II (P60276), and has been shown an activity in human hNav1.3 [17] shifting the activation voltage to much more negative values, effectively opening the channel at resting membrane potentials.

Tityus obscurus To12 (H1ZZI1) is a $\beta$-NaScTx. It shifts the voltage of activation toward more negative potentials thereby affecting sodium channel activation and promoting spontaneous and repetitive firing [18].

The amino acid sequences of $\operatorname{Tm} 1$ and $\operatorname{Tm} 2$ toxins are similar (Additional file 7) to each other and with other NaScTx $[18,19]$ which present activity in mammals and insects sodium channels, although the NaScTx primary sequence does not categorize them as $\alpha-\mathrm{NaScTx}$ or $\beta-\mathrm{NaScTx}$, this difference is only observed experimentally where the $\beta$-NaScTx cause a more negative potential shift.

Only Tm1 showed activity in Nav 1.6 channels, reduction of $63.3 \pm 7 \%(n=3)$ of the current with $1 \mu \mathrm{M}$ of toxin. This special difference may be attributed to some residues in $\mathrm{C}$ - and $\mathrm{N}$-terminal portion of Tm1. Unfortunately, it was not possible to sequence the Tm1 N-terminal Tm1, which could bring more information about its structure/activity. However, we bring to light the difference after the alignment of the cysteines, it is observed the presence of a valine in position 8 , which occurs only in Tm1 and not observed in Tm2 or in the other toxins aligned.

In DUM cell channels Tm 1 also reduced $35 \pm 4.1 \%$ of the current with $1 \mu \mathrm{M}$ of toxin. DUM neurons are important for locomotion, neuromodulation and secreting octopamine that changes the basic tension used in different metabolic substrates of insects [20]. There are only two studies on the activity of scorpionic toxins in DUM cells, a-NaScTx described by Buthus martensi (BmK M1) and other with Buthus occitanus tunetunus (BotIT2) [21,22]. Currently, most assays for insecticidal toxins are in vivo which does not indicate their specific pharmacological action or their molecular target, demonstrating the need for further studies using the "patch clamp" technique with insect neuronal cells (DUM).

Tm1 and Tm2, showed sodium current reduction activity in HEK293 Nav 1.3 cells of $71.5 \%(n=1)$ and $35.81 \pm 10.2 \%$ $(\mathrm{n}=5), \operatorname{Tm} 2$ was also tested in HEK293 Nav 1.3 cells with a $+50 \mathrm{mV}$ depolarizing pulse protocol, the activity of the toxin increased from $35.81 \pm 10.2 \%(n=5)$ to $95.15 \%(n=2)$. This activity of sudden decrease in current with the presence of a previous depolarizing pulse is uncommon in $\beta$-NaScTx. Previous depolarization protocols increase the current in more negative potentials in $\beta-\mathrm{NaScTx}$ assays [23]. This is due to the induction of a conformational change in channel II domain voltage sensor, generated by the pre-pulse, thereby promoting an increase in the binding force of the toxin. In this case, the toxin binding prevents the voltage sensor return to the resting state and reduces the energy needed to open the channel [24]. This difference in amino acids in the $\alpha$-helix region, which forms the loop of the molecule, which is responsible for the interaction with the sodium channels, may be the reason why the Tm 2 toxin showed an unusual activity when pre-pulsating cells HEK293 Nav 1.3, more detailed electrophysiological tests should be carried out to resolve this question. Although Tm1 and Tm2 also promote no shift to more negative potentials, that strongly suggesting that both are $\alpha-\mathrm{NaScTx}$.

The toxins' phylogenetic relationships showed a cluster of Tityus (Archaeotityus) mattogrossensis (Tm1 and Tm2) between subgenus Tityus (Tb2-II, Tf2, Ts2 and To12) and Tityus (Archaeotityus) clathratus (Tcl1and Tcl2). Although a molecular analysis of more Archaeotityus species is needed to evaluate whether they to determine their phylogenetic relation with species in the subgenus Tityus.

\section{Conclusion}

Although Tityus (Archaeotityus) mattogrossensis is considered as an ancient group in Tityus genus, the primary structure of the two isolated toxins ( $\mathrm{Tm} 1$ and $\mathrm{Tm} 2$ ) is more related to Tityus subgenus. Tm 1 and $\mathrm{Tm} 2$ are NaScTx, in patch clamp electrophysiological tests promoting reduction on HEK293 Nav 1.3, DUM and DRG cells. More specifically, only Tm1 had activity on HEK293 Nav 1.6. Tm1 and Tm2 also promote no shift to more negative potentials, strongly suggesting that both are $\alpha-\mathrm{NaScTx}$.

Studies with scorpion toxins are closely related to their sting toxicity and consequent deleterious effects on humans. However, scorpion species not considered to be of medical importance can provide important information about the diversity and evolution of toxin structures.

\section{Availability of data and materials}

All data generated or analyzed during this study are included in this article. 


\section{Funding}

This work was funded by National Council for scientific and technological development $(\mathrm{CNPq})$, the Brazilian Coordination for the Improvement of Higher Education Personnel (CAPES), Federal District Research Support Foundation (FAP-DF) and University of Brasilia Foundation (FUB).

\section{Competing interests}

The authors declare that they have no competing interests.

\section{Authors' contributions}

NBO, ACMM, RDM and ORPJ performed the literature research and wrote the text. JOS. NBO, EAB and CBJ performed and interpretated the mass spectrometry experiments. NBO, CAS, AOS and PSLB performed and interpretated the electrophysiological assays. CAS, RDM and ORPJ conceived this research and designed experiments. NBO, ACMM, CBJ, PSLB, AOS, RDM, EAB and ORPJ read and approved the final manuscript.

\section{Ethics approval}

For Tityus (Archaeotityus) mattogrossensis scorpion collection, permissions were obtained from SISBIO (23408-1) and SISGEN (A826A3A). In addition, the present study was approved by the Animal Use Ethics Committee of University of Brasilia, protocol number 124645/2011.

\section{Consent for publication}

Not applicable.

\section{Supplementary material}

The following online material is available for this article:

Additional file 1. Sequencing of F5 by MALDI-TOF/MS with ISD fragmentation showed a peptide with partial sequence of eight amino acid residues.

Additional file 2. Sequences of the F5 tryptic digestions. The fragmentation was done in lift mode by MALDITOF/MS.

Additional file 3. (A) Current ( $\mathrm{nA})$ and voltage $(\mathrm{mV})$ ratio graph of the Tm1 (1 $\mu \mathrm{M})$ activity (red); control (black). There was no shift to more negative potentials in relation to the control. (B) Protocol performed to obtain the current $\mathrm{X}$ voltage (IxV) register. (C) Sodium current recording from the same cell in which the currents of the $\mathrm{IxV}$ graph were recorded, in black the control sodium current and in red the current under the action of $\operatorname{Tm} 1(1 \mu \mathrm{M})$.

Additional file 4. Sequencing of F6 by MALDI-TOF with ISD fragmentation showed a peptide with partial sequence of 37 amino acid residues.

Additional file 5. Sequences of the F6 tryptic digestions. The fragmentation was done in lift mode by MALDI-TOF/MS.
Additional file 6. (A) Current $(\mathrm{nA})$ and voltage $(\mathrm{mV})$ ratio graph of Tm2 $(1 \mu \mathrm{M})$ activity (red) in HEL293 Nav 1.6 cell; control (black). There was no shift to more negative potentials in relation to the control. (B) Protocol performed to obtain the current $\mathrm{X}$ voltage $(\mathrm{IxV})$ register. $(\mathrm{C})$ Sodium current recording from the same cell in which the currents of the $\mathrm{IxV}$ graph were recorded, in black the control sodium current and in red the current under the action of $\operatorname{Tm} 2(1 \mu \mathrm{M})$.

Additional file 7. Clustal Omega alignment of Tm1 and Tm2 isolated in this work and Tityus bahiensis Tb2-II toxin (P60276), Tityus fasciolatus Tf2 (C0HJM9), Tityus serrulatus Ts2 (P68410); Tityus obscurus To12 (H1ZZI1), Tcl1 Tityus clathratus (J9PJ66) and Tcl2 Tityus clathratus (J9PIJ6). (*) Indicates identical residues, (:) indicates strong conservation, (.) indicates weak conservation sites.

\section{References}

1. Lourenço $W$. The scorpion families and their geographical distribution. J Venom Anim Toxins. 2001;7(1). https://doi.org/10.1590/S010479302001000100002.

2. Lourenço W, Ythier E. The remarkable scorpion diversity in the Ecuadorian Andes and description of a new species of Tityus C. L. Koch, 1836 (Scorpiones, Buthidae). Zookeys. 2013 Jun 5;307:1-13.

3. Rein JO. The Scorpion Files - Buthidae [Internet]. Scorpion Files - NTNU. 2008 [cited 2021 Feb 14]. Available from: https://www.ntnu.no/ub/ scorpion-files/index.php.

4. Ojanguren-Affilastro AA, Mattoni Cl, Ochoa JA, Ramírez MJ, Ceccarelli FS, Prendini L. Phylogeny, species delimitation and convergence in the South American bothriurid scorpion genus Brachistosternus Pocock 1893: Integrating morphology, nuclear and mitochondrial DNA. Mol Phylogenet Evol. 2016 Jan;94(Pt A):59-70.

5. Lourenço W. Nouvelle proposition de découpage sous-générique du genre Tityus C.L. Koch, 1836 (scorpiones, Buthidae). Boletín Soc Entomológica Aragon. 2006;39:55-67.

6. Lourenço WR. A new species of Tityus C.L. Koch, 1836 (Scorpiones: Buthidae) from the island of Martinique, Lesser Antilles. Arthropoda Sel. 2013 Sep;22(3):227-31.

7. Borges A, Jowers MJ, Bónoli S, De Sousa L. Scorpions from the primeval subgenus Archaeotityus produce putative homologs of Tityus serrulatus toxins active on voltage-gated sodium channels. J Venom Anim Toxins incl Trop Dis. 2012;18(4):432-40. https://doi.org/10.1590/S1678-91992012000400012.

8. Porto T, Brazil T, Lira-da-Silva R. Scorpions, state of Bahia, northeastern Brazil. Check List. 2010 May;6(2).

9. Álvares ÉSS, Maria M De, Amâncio FF, Campolina D. [First record of scorpionism caused by Tityus adrianoi Lourenco (Scorpiones: Buthidae). Rev Soc Bras Med Trop. 2006 Jul-Ago;39(4):383-4. [Article in Portuguese].

10. Albuquerque CMR de, Porto TJ, Amorim MLP, Santana Neto P de L. [Scorpionism caused by Tityus pusillus Pocock, 1893 (Scorpiones; Buthidae) in State of Pernambuco.] Rev Soc Bras Med Trop. 2009 Apr;42(2):206-8. [Article in Portuguese].

11. Caliskan F, García BI, Coronas FI V, Batista CVF, Zamudio FZ, Possani LD. Characterization of venom components from the scorpion Androctonus crassicauda of Turkey: peptides and genes. Toxicon. 2006 Jul;48(1):12-22.

12. Debois D, Bertrand V, Quinton L, De Pauw-Gillet M-C, De Pauw E. MALDI-In Source Decay Applied to Mass Spectrometry Imaging: A New Tool for Protein Identification. Anal Chem. 2010 Apr 16;82(10):4036-45.

13. Strong PN, Smith JT, Keana JFW. A convenient bioassay for detecting nanomolar concentrations of tetrodotoxin. Toxicon. 1973 Aug;11(5):433-8.

14. Wagner S, Castro MS, Barbosa JA, Fontes W, Schwartz ENF, Sebben A, Pires Jr OR, Sousa MV, Schwartz CA. Purification and primary structure determination of Tf4, the first bioactive peptide isolated from the venom of the Brazilian scorpion Tityus fasciolatus. Toxicon. 2003 Jun;41(7):737-45. 
15. Pimenta AM, Martin-Eauclaire M, Rochat H, Figueiredo SG, Kalapothakis E, Afonso LC, de Lima ME. Purification, amino-acid sequence and partial characterization of two toxins with anti-insect activity from the venom of the South American scorpion Tityus bahiensis (Buthidae). Toxicon. 2001 Jul;39(7):1009-19.

16. Kalapothakis Y, Miranda K, Pereira AH, Witt ASA, Marani C, Martins AP, Leal HG, Campos-Junior E, Pimenta AMC, Borges A, Chavez-Olortegui C, Kalapothakis E. Novel components of Tityus serrulatus venom: A transcriptomic approach. Toxicon. 2021 Jan 15;189:91-104.

17. Camargos TS, Bosmans F, Rego SC, Mourão CBF, Schwartz EF. The Scorpion Toxin Tf2 from Tityus fasciolatus Promotes Nav1.3 Opening. PLoS One. 2015 Jun 17;10(6):e0128578.

18. Guerrero-Vargas JA, Mourão CBF, Quintero-Hernández V, Possani LD, Schwartz EF. Identification and Phylogenetic Analysis of Tityus pachyurus and Tityus obscurus Novel Putative Na+-Channel Scorpion Toxins. PLoS One. 2012 Feb 15;7:e30478.

19. Gurevitz M, Karbat I, Cohen L, Ilan N, Kahn R, Turkov M, Stankiewicz M, Stuhmer W, Dong K, Gordon D. The insecticidal potential of scorpion beta-toxins. Toxicon. 2007 Mar 15;49(4):473-89.
20. Grolleau F, Lapied B. Dorsal unpaired median neurones in the insect central nervous system: towards a better understanding of the ionic mechanisms underlying spontaneous electrical activity. J Exp Biol. 2000 Jun;203(Pt 11):1633-48.

21. Brône B, Tytgat J, Wang D-C, Van Kerkhove E. Characterization of $\mathrm{Na}$ + currents in isolated dorsal unpaired median neurons of Locusta migratoria and effect of the alpha-like scorpion toxin BmK M1. J Insect Physiol. 2003 Mar;49(2):171-82.

22. Borchani L, Mansuelle P, Stankiewicz M, Grolleau F, Cestèle S, Karoui $H$, Lapied B, Rochat H, Pelhate M, el Ayeb M. A new scorpion venom toxin paralytic to insects that affects $\mathrm{Na}+$ channel activation. Purification, structure, antigenicity and mode of action. Eur J Biochem. 1996 Oct 15;241(2):525-32.

23. de la Vega RCR, Possani LD. Novel paradigms on scorpion toxins that affects the activating mechanism of sodium channels. Toxicon. 2007 Feb;49(2):171-80.

24. Cestèle S, Yarov-Yarovoy V, Qu Y, Sampieri F, Scheuer T, Catterall WA. Structure and function of the voltage sensor of sodium channels probed by a beta-scorpion toxin. J Biol Chem. 2006 Jul 28;281(30):21332-44. 